\title{
Comprehensive risk assessment of electric power market reform
}

\author{
YANG Rui-xing ${ }^{1, a}$, Tang Tian-qi ${ }^{2, b}$ \\ ${ }^{1}$ Changsha University of Science and Technology, Changsha 410114,P.R.China \\ ${ }^{2}$ North China Electric Power University ,Beijing 102206,P.R.China \\ a227262318@qq.com \\ b715437085@qq.com
}

Keywords: Electricity market reform; Risk assessment; Cost - Benefit Analysis; Lucas Critique . Abstract. With the development of market economy, complexity of market environment, strengthening legal supervision, increased operational risk and competition and other reasons, risk awareness has gradually increased in more and more industries and enterprise, therefore risk management is increasingly paid attention to. Electricity market is an important part of the electric power industry, and it is an important means of optimizing resource allocation in large scale and achieving energy strategy layout. To promote the construction and development of UHV power grid, which as the backbone of a strong smart grid, adapt to a wide range of clean energy access, meet the demand side of the market, improve energy conservation requirements and other market-based mechanisms, trade patterns of electricity inevitably toward diversification direction, electricity trading range will be gradually expanded. However, the transformation of the company's development also have put forward higher requirements to cross inter-provincial electricity trade optimal allocation of resources, standard construction of the trading system, electricity market service and company's operations and decision-making. In order to prevent and resolve power market trading risk at work effectively, to further promote the "two transformations", have launched a comprehensive risk assessment work in the electricity market is particularly important. Combined with electricity market reform and feature analysis, this paper is mainly to solve electricity market reform program, electricity market building programs, based on the design and implementation of trading variety to proof scientific, repeatedly balance the pros and cons, analyzing who is the main benefit, who is impaired subjects, the adjustment of interests whether fair, what is the cost of reform, what is the benefit of reform , and how about the risk. Using cost - benefit analysis, quantitative impact estimates, and stress tests to do comprehensive risk assessment for a variety of electricity market reform program, scientific planning, do proactively plan, improve the scientific and standardization level of electricity market reform program, try to minimize the risk of electricity market reform program.

\section{Introduction}

China has special national conditions, the basic features of electricity market are: first, the independence of market participants. For a long time, China electric power implements government monopoly control, electric power enterprises are almost state-owned enterprises, in the process of market-oriented the, dependence of the state-owned power enterprises and will be weaken gradually, independence and autonomy will be gradually increase, autonomy expands. It includes not only the right to choose behavior, profit mode, including the choice of system power. Second, the decentralization of economic decision-making. The government will gradually withdraw from the field of microeconomic decisions, and only play a role in macro-control and other essential areas, from plan to manage all to market self- regulation, this process will show the government withdraw from certain areas. Third, market main body structure is diversification. Historically, market economy evolved from the private economy, not laissez-faire, it is restricted and regulated by laws, rules and regulatory . Thus, legalization and standardization is an important indicator of the market. Main body of participating market competition will increase, diversified, no longer the monopoly by state-owned power companies The market may also have a lot of features, but these are the most basic features. 
Power industry related to people's livelihood, reform risk is bigger than the general competitive industry, in case of making mistakes, it will affect the overall economic development, and even a serious impact on social stability, California electricity crisis is a case, therefore, every state should cautious about electricity reform. China's power market reform exist three major risks: First, the risk of socio-economic development; the second is the risk of increased costs caused by rising electricity prices; third is the risk of coordination mechanisms.

The power industry an important industry which is related to socio-economic development and people's lives, under the premise of China's market economy system has been initially established and market-oriented reforms and national administrative control coexist, power companies are faced with both operational risk and financial risk under market economy conditions, but also facing the risk of operating mechanism. Doing a comprehensive risk assessment for electricity market reform program is essential.

\section{Comprehensive risk assessment of electricity market reform program domestic and foreign}

International common practice of comprehensive risk assessment, generally when introduce significant reform policies, using a series of policy assessment tools to calculate cost and cashier, which play an important role to grasp reform and balance the interests of all parties.

Therefore, we should avoid electricity market reform program into a war of words, one important aspect is the use of cost - benefit analysis, quantitative impact estimates, and stress tests to do comprehensive risk assessment for a variety of electricity market reform program, scientific planning, do proactively plan, improve the scientific and standardization level of electricity market reform program, try to minimize the risk of electricity market reform program.

\section{Comprehensive risk assessment method for electricity market reform program}

Using cost - benefit analysis, to grasp market reform power

Interest adjustment is a difficult problem in the reform of electricity market, and the cost - benefit analysis method is a new development which reflect international policy .

Cost - benefit analysis is a approach which by considering direct benefits and costs, indirect benefits and costs in a reform, evaluate feasibility analysis comprehensively and compare the pros and cons of different programs, in order to achieve social welfare maximization.

Introducing cost-benefit analysis, to minimize cost and maximize revenue can be formulated into the basic constraint conditions of electricity market reform program, to correct the following two undesirable tendencies: it is helpful to correct tendency of merely focus on needs, regardless cost when make decisions. In some cases do require some decisions, but considering its high cost is not worth the reform, it must be discarded. Second, it helps to correct the tendency that only consider the cost, without considering the benefits. In some cases, even if some electricity market program implementation has huge costs, but the benefits will be greater, combined economic and social benefits, the electricity market reform plan is feasible.

Cost - benefit analysis generally includes four steps:

(1) Determining the effects and results of the electricity market reform program, and for different market players will be divided into costs or benefits;

(2) Giving different costs and benefit value;

(3) Given the impact of some of the electricity market reform program embodied in a longer period, we need to use some parameters to balance the current value and future impact ;

(4) Comparing direct and indirect, immediate and long-term costs and benefits in different electricity market reform program . The scientific of cost - benefit analysis method is to speak with facts and figures, making electricity market-oriented reforms and revenue clear, helping gather people's consensus. But there are also more concerned about the tendency of efficiency targets, which requires a good balance to development in electricity market-oriented reforms. 
Introducing quantitative impact measurement mechanism,mastering electricity market reform power.

By measuring and comparing the impact of different reform programs on key economic or social variables, on the one hand, it can help the decision makers to grasp the impact of different reform programs and the expected consequences accurately; On the other hand, it can sort out the transmission mechanism and the key link, and strengthen the process control of the reform. That is, the quantitative impact measurement can be detected "water depth", then guide the next step .

Be good at stress testing, control electricity market reform risk

Stress testing is a tool for throughout bottom line thinking. On the level of using, the pressure test can be divided into top-down macro approach and bottom-up micro approach. From top to bottom, all test objects are considered as a whole, and the test is carried out, such as the effect of economic growth and fluctuation on employment. From bottom to top, it is test the micro individual level, and then summarize the overall results, such as economic and financia impact of real estate price changes.

Refer to the "Lucas critique", stabilizing the electricity market reform expectation

"Lucas critique" requires when we formulate and promulgate any policy, we should fully consider decision adjustments which made by market players, so that we can plan advance and achieve the goal. The significance of this method lies in the fact that revealed any policy is the game between the government and the market players, if the government regard market players as passive "machine" to control, the execution effect will be greatly reduced. Thus, intensity of the electricity market reform must be matched with the social endurance phase.

\section{Summary and Outlook}

The assessment tool can serve the whole process of electricity market reform. During the start-up phase, using cost - benefit analysis to demonstrate the feasibility of electricity market reform; in the stage of making market model and rule, we can use quantitative analysis method and predict the effect of market model and rule, and adjusted according to the rhythm of electricity market reform; Through the stress test to determine the risk of electricity market reform program, preparing risk warning and contingency plans, and effectively keep the bottom line; in the whole process of formulation and implementation of electricity market reform program, we can refer to the "Lucas critique" approach : do electricity market reform advocacy and communication, make common sense, making social expectations stable. As shown below: 


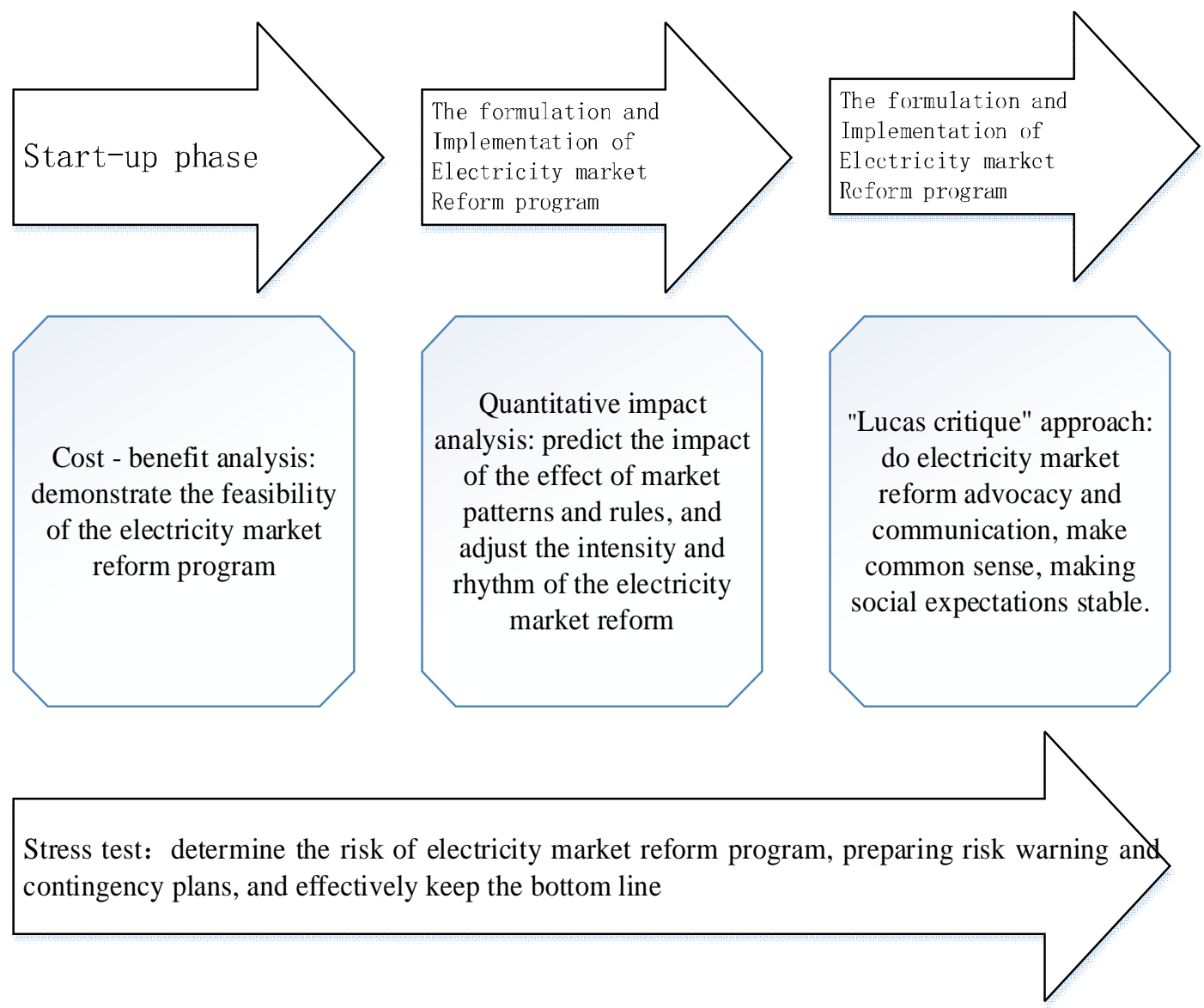

Figure 1 Application of each method in the whole process of electricity market reform In addition, we take a outlook for future electricity market reform, there may be the following risks: (1) Backward consciousness: as a complete market, it must be conducive to introduce competition, through competition, to strengthen management, reduce operating costs, optimize the allocation of social resources. China's electricity market reform has been launched, the power generation companies have realized separation, if want to improve the market, it is necessary to open the sale side of electricity market, realize the linkage of sale price and grid purchase price.

(2) The law is not perfect: China's current "power law" and related laws, regulations are not adapted to the needs of market reform, electric power legislation is imperative. The current law is not perfect, which will bring the corresponding risk of operation management and safety management.

(3) Market discipline problem: a perfect market, which must have rules that adapt to the market and be conducive to operate effectively. Market rules should reflect the regional characteristics of the market, the power grid structure and other factors. Therefore, as power grid company, it should do research actively, considering the problems and difficulties existing in the safe production and operation management, and the problems encountered after, we have to make it clear, feedback to relevant departments actively, so that making rules clear.

\section{References}

[1]Shang Jincheng,Tan Zhongfu. Theory and application of power market risk control.Beijing: China Electric Power Press, 2014.10.

[2]Zhao Jinfeng. The risk management of Power Grid Corp and the reform of electricity market[J]. Modern electric power, 2004, 21(3):102-106.

[3]Ye Xiu. Reform of China Electric Power Market[D]. Fudan University,2010. 